\title{
Eating Disorders in Children and Adolescents. An Updated Review on Screening Methods
}

\author{
LEȚI Maria-Mădălina ${ }^{1}$, POP Anca Lucia ${ }^{2,3}$, GARNER David ${ }^{4}$, DOBRESCU \\ Iuliana $^{1,3}$
}

${ }^{1}$ Clinical Hospital of Psychiatry "Prof. Dr. Alexandru Obregia", Romania

${ }^{2}$ National Institute of Diabetes, Nutrition and Metabolic Diseases "Prof. Dr. N. Paulescu" Romania

${ }^{3}$ University of Medicine and Pharmacy "Carol Davila" Bucharest, Romania

${ }^{4}$ President, Department of Psychology, River Centre Clinic, United States of America

*Corresponding author:ancapop@hotmail.com

\begin{abstract}
This article aims to review the screening and diagnostic tools for eating disorders (ED). Eating disorders represent a complex pathology defined by an imbalance between hunger and satiety, installed in an emotional, traumatic, or conflictive context. Recently, the emphasis regarding ED is focused on the link between genetics, the mental pathology, and the somatic and metabolic phenotype and early detection. Early detection and intervention can assure a better recovery and can improve a lot the quality of life of these patients. Methods: We selected ten articles of central importance on the topic in a systematic search on eight databases, articles selected on the type of scales, and size of the study. Results: We identified eight questionnaire scales used in large trials in ED disorders in the scanned literature, choose because we consider it the most accurate and the ones that evaluate best the pathology and the elements that are important as specific traits in ED. There are interview-type scales and self-administered scales. Interview scales are characterized by assessments of symptoms and diagnosis, while self-administered assess particular traits and the possibility of further development of eating disorders. The majority of the scales evaluated were described and used in adult populations. From all the scales assessed and analyzed, only three are described at the child population - it is EAT-26 (> 16 years), EDI-3 (>13 years), and ANSOCQ (> 13 years). Conclusions: It is essential to develop specific scales for people under 18 years of age, given the increasing incidence of ED among children and the need for early detection and appropriate intervention. Early detection of ED in children implies a simple and accurate evaluation at the primary care level or in schools, as the course of the disease can be subclinical for several years. Moreover, the need for accurate scales and telemedicine testing and diagnosis is of high importance during the COVID-19 pandemic as youth are at particular risk being psychologically affected due to disrupted education and social interactions - at a critical time.
\end{abstract}

Keywords: eating disorders, anorexia nervosa, bulimia nervosa, personality traits, screening tools, Covid-19

\section{Introduction}

The Eating Disorders represent a pathology which is among us since the beginning of the civilization - in Ancient Greek women from the high-class society fasting themselves to be thinner and to be perceived well by the people [1]. Feeding is the most crucial initial step for the connection between mum and child. According to DSM-V - The Diagnostic and Statistical Manual of Mental Disorders, the central eating disorders (EDs) described in the early years of life are pica, rumination, then in adolescence - anorexia nervosa (AN), bulimia nervosa (BN) and the newly introduced Night Eating Syndrome (ENS) [13,32]. Besides the somatic disturbances, the ED pathology specter includes emotional instability and a nutritional imbalance. Even though with the appropriate therapeutic approach, there are extended periods of remission, 30-50\% of cases relapse. The setting out can be in childhood, between 5 and 12 years; first is noticed by the close environment (family, friends, school, family doctor), but usually neglected or ignore the pathology due to insufficient knowledge about an adequate diet. 
During the COVID-19 pandemic, children are at particular risk due to disrupted education and social interactions - at a critical time. [34]. Early detection implies a simple and accurate evaluation at the primary care level, in the early stages, both in adults and, more importantly, in children often undiagnosed for an average of 4 to 12 years. For this purpose, several screening interview scales are available (not freely accessible), a few of them feasible for the pediatric population.

Several types of scales are currently used - (a) self-report questionnaires -EDI-3, BSQ, TFEQ, MAC, BULIT-R, QEWP-R, EDE-Q, EAT, NEQ - and other; (b) semi-structured interviews - SCID-I, EDE - and other; (c) clinical interviews unstructured or observer-based rating scales- Morgan Russel scale [33, 1]. Less is known about the better selection of the most sensitive and accurate scale for children, the implementation level, and outcomes in our country and also worldwide.

Aim of the study: to overview the available screening scales for ED (especially AN and $\mathrm{BN}$ ) and use in clinical trials and identify research and practice gaps in screening AN and BN, the search was made specially to see which one applies to the pediatric populations. We test the literature for the available screening tools in ED and studies using the scales. Data sources: we made an accurate search in the primary sources of Databases (PubMed, BMC Public Health, Global Health, Cross Ref, Scopus, Web of Science, Google Scholar and Medline) with the keywords: "screening eating disorders," "intervention Anorexia Nervosa," "intervention eating disorders," "screening Bulimia Nervosa." Binge-Purge subtype. Forty studies using AN and BN scales with a clinical eating disorder group with or without a control group were identified. Of these, eight were included in the present study (Table 1).

Scales reviewed in the current paper:

- EDE - useful for the clinician to observe the pathology and evaluate the primary and specific characteristics regarding the present moment of disease.

- $\quad$ EDE-Q - semi-structured and administered by a qualified person, takes a long time for administration; a self-administered questionnaire that assesses the severity of symptoms and how somatic features are altered weight, height, menstruation. For good accuracy, it is preferable to use it together with another questionnaire that better evaluates the specific symptoms [16].

- EDI - over 13 years; evaluate the specific characteristics of $\mathrm{AN}$ and BN; Now is available the third version, with 91 items, 12 subscales that assess the particular aspects; it also evaluates the weight.

- $\quad$ EAT - 26 item - over 16 years; also evaluate somatic features-weight, height and the specific behaviours that determine eating disorders

- SWEAA - self-reported questionnaire, administered to children with autism spectrum disorder and average intellect, which have particularities of eating behaviour [18]

- $\quad$ CIA 3.0 - self-reported questionnaire; evaluates the specific features of eating disorders and complete the clinical diagnosis [22]

- SCOFF - the test includes five simple questions addressed to patients in primary care units by clinicians to facilitate if there is a suspicion of a diagnosis of ED. It has a very high sensitivity. Not enough data to consider the validity and reliability and the possibility of using it to screen ED in the general population. But it can still be used in primary medicine care for patients considered at risk for ED After application. The clinician evaluates the existence of ED diagnosis and the necessity of the referral to a specialist for a complex evaluation [7,20].

ANSOCQ - over 14 years; reliable and self-report questionnaire - assess the readiness for change and motivation, 20 items, it is used to evaluate the wish of change of the persons already diagnosed with AN. Lickert Scale CUT-OFF 2,5; As the scores on these scales are more significant, the person is more motivated to change (made after the stages of change model - DiClemente and Prochaska 1998 - pre-contemplation, contemplation, preparation, action, maintenance).

\section{Results}

Ten articles of central importance on the topic were identified in a systematic search on eight databases, articles selected on the type of scales and size of the study; we identified nine questionnaire scales used in large trials in ED disorders in the scanned literature for the most accurate scales (Table 1). 
To observe the personality traits, the clinician may use SCID II Interview - a structured interview used in persons who already have the diagnostic, and it helps to follow the specific characteristics. It also evaluates the personality disorder - used at the persons that already have a diagnostic of $\mathrm{AN}$, the most common types of personality were avoidant (13\%), followed by borderline (9\%), obsessive-compulsive (8\%) and antisocial (7\%) [32].

It's good to know that the devastating effects of eating disorders didn't affect only the persons who have the pathology but also the family and the people around it. It is well known that the Anorexia Nervosa has the highest rate of mortality from all eating disorders (up to 10\% [6]), and it's one of the most common pathologies in adolescents, over asthma or diabetes. There is a high risk of suicide, severe depression, alcohol abuse, substance dependence, or significant stress in this kind of person $[12,15]$. The rate of mortality rises if there are comorbidities like significant depression or addiction [5].

In many cases, it was reported that there is a pre-existing cerebral dysfunction regarding structural or neurochemical fields. Studies in recent years open new perspectives that support the existence of specific pre-existing genetic mutations in eating disorders (modified locus on chromosome 12 rs4622308) [1]. According to Rahkonen \& al., in 2016 the eating disorders affected up to $4 \%$ of persons around the world; the most frequent being Anorexia Nervosa, followed by binge eating and less expanded, is Bulimia Nervosa [3]. Unfortunately, less than $10 \%$ of people address to a doctor, and up to $70 \%$ have psychiatric comorbidity. SalbachAndrae \& al. discovered that 25-29\% of Anorexia Nervosa cases associated with ObsessiveCompulsive Disorder (OCD), and up to $79 \%$ would develop an episode during life [14].

It is evident that in ED, there is a genetic vulnerability. History of anxiety disorders, depression, alcoholism, or "schizo" spectrum disorders are usually present in this kind of patients [13, 28].

The Global Burden of Disease Study published the results in 2015 states that AN and BN are responsible for 1.9 million people affected globally by burden -chronic and disabling diseases lasting over long periods measured by DALY (disability-adjusted life year). Unfortunately, there are not enough studies on large population groups to accurately characterize the profile of these disorders, but the inclusion in the Global Burden of Disease marks a critical moment and increases the need for prevention and early detection, requiring the attention of Public Health Services [2].

It is essential to know that nutritionist or endocrinologist treats obesity and it's not considered a mental disease; It is regarded as a metabolic disease even though in many cases it has been demonstrated an overlap of specific personality traits and behaviors that aggravates and sustain the disorder. In a group of diabetic patients from Romania, most of them obese, it has been proved that anxiety and depression are usually met $[6,7]$. Also, we are not talking about malnourishment or sub nutrition in this paper. These are fundamental Heath service problems and worldwide, and it is due to poverty, but this can determine low school performance or other emotional imbalances. Unfortunately, during the Covid-19 pandemic, billions of children didn't receive the food anymore from their schools.

The psychological impact of the recent COVID-19 quarantine on ED patients are PTSD symptoms, confusion, boredom, anger, anxiety, increased risk of relapses. The period may amplify compulsive eating and favored diets due to the fear of infection, sedentary lifestyle, social isolation, strict hygiene [33].

Regarding the somatic impact of ED, AN is the most affected and presents a wide range of changes on various organs and systems; the most important are functional amenorrhea, dysfunction of the hypothalamic-pituitary-ovarian axis, impaired fertility [27].

From studying the literature, in the present study, we identified several types of issues linked to the ED: lack of public health programs, late diagnoses, lack of information for teachers and parents in child ED aspects and risk factors, low access or addressability of the patients to the 
specialized clinicians (psychologists, psychiatrists), limited access to screening for the behalf of primary healthcare professionals (GP's, school doctors, nutritionists, school nurses, dentists, pediatricians), low capacity of management the ED disorders in quarantine situations.

The issues linked with ED questionnaires in ED and ED literature regarding early diagnosis and screening scales studies: translation, validity, accuracy, reproducibility were taken into account in the analyzed studies and met all the conditions for statistical validation.

The evaluation method is an essential element - some questionnaires are self-administered, others are by clinical interview. We believe that a trained person is needed to apply these questionnaires and to explain leisurely what each item represents and how it should be best interpreted.

\section{Conclusions}

There is more than ever essential to know that by intervention in the field of teenagers, especially in their school and families, we have a chance to prevent the development of eating disorders and to stop unrealistic perceptions of the body image. Among the risk factors to develop eating disorders are the bullying phenomena due to body weight, the lack of physical activity in schools, small meals, restrictive diets, social/online/family unrealistic beauty standards that are accessible from the period of childhood. An essential number of preventing programs for ED risk factors have developed in the world [17].

A broad topic about prevention and intervention will be the topic of our future research. In this study, we only evaluate the screening and diagnostic. The auto-administered scales give liberty to the person to express how they feel but has the disadvantages that can be misunderstood. It often happens that people with eating disorders, especially those with anorexia nervosa, avoid giving accurate answers about symptoms, hide many behaviors, and consider their behavior to be normal [30].

The majority of the scales used were described and used in adult populations. From all the scales evaluated and analyzed, only three are described at the child population - it is EAT-26 (children above 16 years), EDI-3 (children above 13 years), and ANSOCQ (children above 13 years). One of the scales that we presented in this paper is used after the diagnostic is made (ANSOCQ) and help the clinician to evaluate the stage and to understand how much work he has to do and what levels need to be improved.

The present study evaluates the actual scales used in the screening and follow-up of the nutritional psychiatric pathologies. The next step is the application of selected questionnaires or a combination of during a future coordinated clinical trial to objectively evaluate the best form in screening the ED in youth. It is essential to develop specific scales for people under 18 years of age, given the increasing incidence of ED among children and the need for early detection and appropriate intervention. Moreover, the urgent need for accurate scales and telemedicine testing and diagnosis tools are of high importance during the COVID-19 pandemic as youth are at particular risk - at a critical time.

Declaration of interests: the authors declare no conflict of interests. Funding: No funding to declare.

\section{REFERENCES}

1. Schmidt, U., Adan, R., Böhm, I., Campbell, I. C., Dingemans, A., Ehrlich, S., \& Himmerich, H. (2016). Eating disorders: the big issue. The Lancet Psychiatry, 3(4), 313-315.

2. Vos, T., Barber, R. M., Bell, B., Bertozzi-Villa, A., Biryukov, S., Bolliger, I., \& Duan, L. (2015). Global, regional, and national incidence, prevalence, and years lived with disability for 301 acute and chronic diseases and injuries in 188 countries, 1990-2013: a systematic analysis for the Global Burden of Disease Study 2013. The Lancet, 386(9995), 743-800

3. Keski-Rahkonen, A., \& Mustelin, L. (2016). Epidemiology of eating disorders in Europe: prevalence, incidence, comorbidity, course, consequences, and risk factors. Current opinion in psychiatry, 29(6), 340-345. 
4. Markkula, N., Härkänen, T., Perälä, J. (2012) Mortality in people with depressive, anxiety and alcohol use disorders in Finland - The British Journal of Psychiatry - cambridge.org

5. Rikani, A. A., Choudhry, Z., Choudhry, A. M., Ikram, H., Asghar, M. W., Kajal, D., \& Mobassarah, N. J. (2013). A critique of the literature on aetiology of eating disorders. Annals of neurosciences, 20(4), 157.

6. Yager, J., Roy-Byrne, P.P., Solomon, D., (2020) Eating disorders: Overview of epidemiology, clinical features, and diagnosis - Up To Date

7. Morgan, JF Reid, F., Lacey, J.H.; (1999) The SCOFF questionnaire: assessment of a new screening tool for eating disorders - BMJ

8. MA Cotton, C Ball, P Robinson (2003)Four simple questions can help screen for eating disorders Journal of General Internal Medicine

9. Leți, M.M., Bodnărescu-Cobanoglu M., Dobrescu I., Pop A. L., Popa D., Rosu I. A., Iorgut C., Zetu C. (2018)The Prevalence and Characteristics of Depression in Diabetes Mellitus Patients. Is Routine Screening Of Depression Necessary In The Diabetes Patients?

10. Leți, M.M., Bodnărescu-Cobanoglu M., Pop A. L., Voiculescu, B., Popa D., Rosu I. A., Iorgut C., Zetu C. The prevalence and characteristics of anxiety in diabetes mellitus patients - Prezentare Orala - Conferinta Academia Romana - 2018

11. Allen, K. L., Byrne, S. M., Oddy, W. H., \& Crosby, R. D. (2013). DSM-IV-TR and DSM-5 eating disorders in adolescents: Prevalence, stability, and psychosocial correlates in a population-based sample of male and female adolescents. Journal of Abnormal Psychology, 122(3), 720-732. https://doi.org/10.1037/a0034004

12. Harrington, B. C., Jimerson, M., Haxton, C., \& Jimerson, D. C. (2015). Initial evaluation, diagnosis, and treatment of anorexia nervosa and bulimia nervosa. American Family Physician, 91(1), 46-52. Harriet Salbach Andrae, Klaus Lenz, Nicole Simmendinger, Nora Klinkowski, Ulrike Lehmkuhl, Ernst Pfeiffer Psychiatric Comorbidities among Female Adolescents with Anorexia Nervosa - Child Psychiatry and Human Development volume 39, pages 261-272(2008)

13. Root, T. L., Pinheiro, A. P., Thornton, L., Strober, M., Fernandez-Aranda, F., Brandt, H., ... \& Kaplan, A. S. (2010). Substance use disorders in women with anorexia nervosa. International Journal of Eating Disorders, 43(1), 14-21.

14. Paxton, S. J., \& Damiano, S. R. (2017). The development of body image and weight bias in childhood. In Advances in child development and behavior (Vol. 52, pp. 269-298). JAI.

15. Le, L. K. D., Barendregt, J. J., Hay, P., \& Mihalopoulos, C. (2017). Prevention of eating disorders: a systematic review and meta-analysis. Clinical Psychology Review, 53, 46-58.

16. Mond, J. M., Hay, P. J., Rodgers, B., Owen, C., \& Beumont, P. J. V. (2004). Validity of the Eating Disorder Examination Questionnaire (EDE-Q) in screening for eating disorders in community samples. Behaviour research and therapy, 42(5), 551-567.

17. Garner, D. M., Olmstead, M. P., \& Polivy, J. (1983). Development and validation of a multidimensional eating disorder inventory for anorexia nervosa and bulimia. International journal of eating disorders, 2(2), 15-34.

18. Karlsson, L., Råstam, M., \& Wentz, E. (2013). The Swedish Eating Assessment for Autism spectrum disorders (SWEAA) - validation of a self-report questionnaire targeting eating disturbances within the autism spectrum. Research in Developmental Disabilities, 34(7), 2224-2233. Maria C. Raciti, B.A. John C. Norcross The EAT and EDI: Screening, Interrelationships, and Psychometrics - International Journal of Eating Disorders, Vol. 6, No. 4, 579-586 (1987)

19. Jenkins, P. E. (2013). Psychometric validation of the Clinical Impairment Assessment in a UK eating disorder service. Eating behaviors, 14(2), 241-243.

20. Morgan, J. F., Reid, F., \& Lacey, J. H. (1999). The SCOFF questionnaire: assessment of a new screening tool for eating disorders. Bmj, 319(7223), 1467-1468.

21. Cotton, M. A., Ball, C., \& Robinson, P. (2003). Four simple questions can help screen for eating disorders. Journal of General Internal Medicine, 18(1), 53-56.

22. Lantz, E. L., Gillberg, C., Råstam, M., Wentz, E., \& Lowe, M. R. (2017). Premorbid BMI predicts bingepurge symptomatology among individuals with anorexia nervosa. International Journal of Eating Disorders, 50(7), 852-855.

23. Nilsson, E. W., Gillberg, C., Gillberg, I. C., \& Raastam, M. (1999). Ten-year follow-up of adolescentonset anorexia nervosa: personality disorders. Journal of the American Academy of Child \& Adolescent Psychiatry, 38(11), 1389-1395.

24. Poterasu, M., Rowland, D. L., Ciobanu, C., \& Fica, S. (2020). Anorexia nervosa and reproduction: connecting brain to gonads. Journal of Mind and Medical Sciences, 7(1), 1-8.

25. Grigoroiu-Serbanescu, M., Magureanu, S., Milea, S., Dobrescu, I., \& Marinescu, E. (2003). Modest familial aggregation of eating disorders in restrictive anorexia nervosa with adolescent onset in a Romanian sample. European child \& adolescent psychiatry, 12(1), i47-i53.

26. Le, L. K. D., Barendregt, J. J., Hay, P., \& Mihalopoulos, C. (2017). Prevention of eating disorders: a systematic review and meta-analysis. Clinical Psychology Review, 53, 46-58. 
27. Yahalom, M., Spitz, M., Sandler, L., Heno, N., Roguin, N., \& Turgeman, Y. (2013). The significance of bradycardia in anorexia nervosa. International Journal of Angiology, 22(02), 083-094.

28. Beglin, S. J., \& Fairburn, C. G. (1992). Women who choose not to participate in surveys on eating disorders. International Journal of Eating Disorders, 12(1), 113-116.

29. Fairburn, C. G., \& Beglin, S. J. (2008). Eating disorder examination questionnaire. Cognitive behaviour therapy and eating disorders, $309,313$.

30. Ramklint, M., Jeansson, M., Holmgren, S., \& Ghaderi, A. (2010). Assessing personality disorders in eating disordered patients using the SCID-II: Influence of measures and timing on prevalence rate. Personality and individual differences, 48(2), 218-223.

31. Brooks, S. K., Webster, R. K., Smith, L. E., Woodland, L., Wessely, S., Greenberg, N., \& Rubin, G. J. (2020). The psychological impact of quarantine and how to reduce it: rapid review of the evidence. The Lancet.

32. 1 Allison, K. C., Lundgren, J. D., O'Reardon, J. P., Geliebter, A., Gluck, M. E., Vinai, P., ... \& Engel, S. (2010). Proposed diagnostic criteria for night eating syndrome. International Journal of Eating Disorders, 43(3), 241-247.

33. Morgan, H. G., \& Hayward, A. E. (1988). Clinical assessment of anorexia nervosa: the Morgan-Russell outcome assessment schedule. The British Journal of Psychiatry, 152(3), 367-371.

34. Douglas, M., Katikireddi, S. V., Taulbut, M., McKee, M., \& McCartney, G. (2020). Mitigating the more far-reaching health effects of covid-19 pandemic response. Bmj, 369.

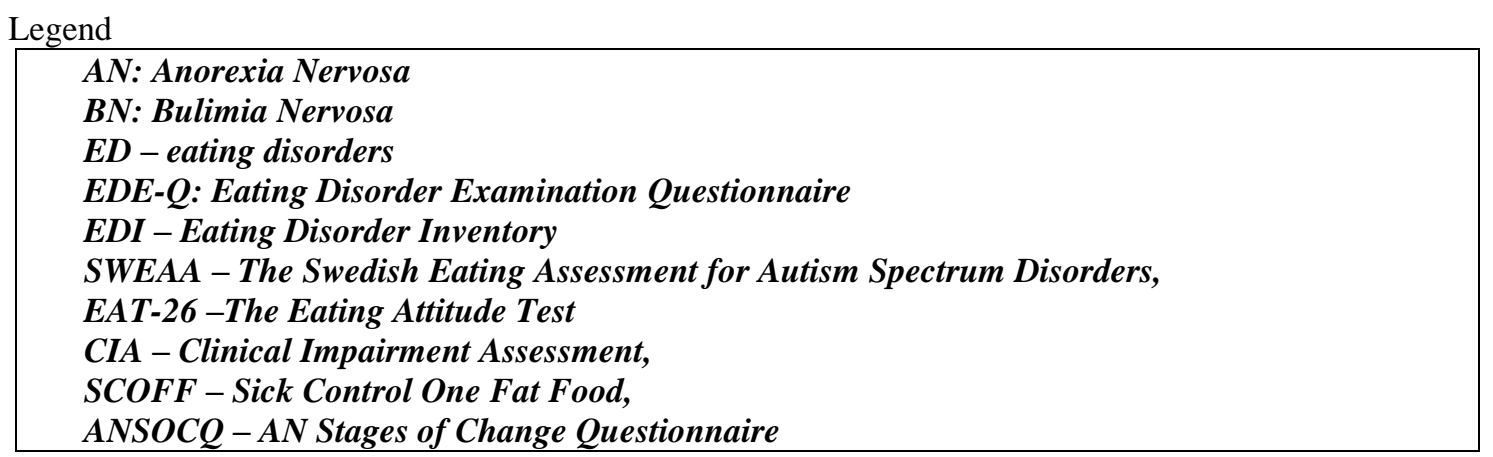

ANNEX - Table I. Selected studies of correlations - specific screening and evolution methods in eating disorders - described on adult populations mostly (ED) - Total participants $=2797$

\begin{tabular}{|c|c|c|c|c|c|c|}
\hline $\begin{array}{l}\text { Study } \\
\text { participants }\end{array}$ & $\begin{array}{l}\text { Scale } \\
\text { used }\end{array}$ & $\begin{array}{l}\text { Year/d } \\
\text { uration }\end{array}$ & Control & Method & Results & Reference \\
\hline \multirow[t]{2}{*}{$\mathrm{N}=802$} & \multirow[t]{2}{*}{ EDE-Q } & $\begin{array}{l}2003 / 1 \\
\text { year } \\
\text { follow } \\
\text { up? }\end{array}$ & - & \multirow{2}{*}{$\begin{array}{l}\text { Compared EDE, an semi- } \\
\text { structured interview, self- } \\
\text { reported. The study } \\
\text { recruited persons in } 2 \\
\text { phases. It is a good } \\
\text { measure for real cases- a } \\
\text { superior self-reported } \\
\text { measure. Useful in two- } \\
\text { phase epidemiological } \\
\text { studies }\end{array}$} & \multirow{2}{*}{$\begin{array}{l}\text { It has been } \\
\text { proved that the } \\
\text { scale is feasible } \\
\text { to be used in } \\
\text { prospective } \\
\text { epidemiologica } \\
1 \text { studies. }\end{array}$} & \multirow[t]{2}{*}{$\begin{array}{ll}\text { Mond \&al. } \\
2003 \text { [18] }\end{array}$} \\
\hline & & \multicolumn{2}{|c|}{$\begin{array}{l}\text { participants - general } \\
\text { population } \quad(18-45 \\
\text { years), remain } 208\end{array}$} & & & \\
\hline $\begin{array}{l}\mathrm{N}=243 \text { young } \\
\text { women }\end{array}$ & EDE & $\begin{array}{l}1994 \\
\text { Reeval } \\
\text { uate at } \\
28 \text { days }\end{array}$ & $\begin{array}{l}\text { No } \\
\text { control }\end{array}$ & $\begin{array}{l}\text { Investigator-based } \\
\text { Interview. It will be } \\
\text { administered } \\
\text { periodically for a period } \\
\text { of time } \\
\text { More fileds evaluated } \\
\text { - restraint, eating } \\
\text { concern, shape concern, } \\
\text { weight concern }\end{array}$ & $\begin{array}{l}\text { It's very good } \\
\text { rated as an } \\
\text { interview for } \\
\text { evaluating the } \\
\text { simptoms and } \\
\text { put } \\
\text { diagnostic of } \\
\text { ED }\end{array}$ & $\begin{array}{l}\text { Fairburn et al } \\
2008\end{array}$ \\
\hline $\begin{array}{l}\mathrm{N}=670 \\
113-\mathrm{AN}\end{array}$ & EDI & 1983 & $\mathrm{~N}=557$ & $\begin{array}{l}\text { Cross-validation } \\
\text { procedure. It was } \\
\text { considered internal } \\
\text { consistency for all } \\
\text { subscales and some }\end{array}$ & & \begin{tabular}{l}
\multicolumn{1}{c}{ First } \\
developed by \\
Garner $\quad \&$ \\
Polivy in 1983 \\
{$[19]$}
\end{tabular} \\
\hline
\end{tabular}




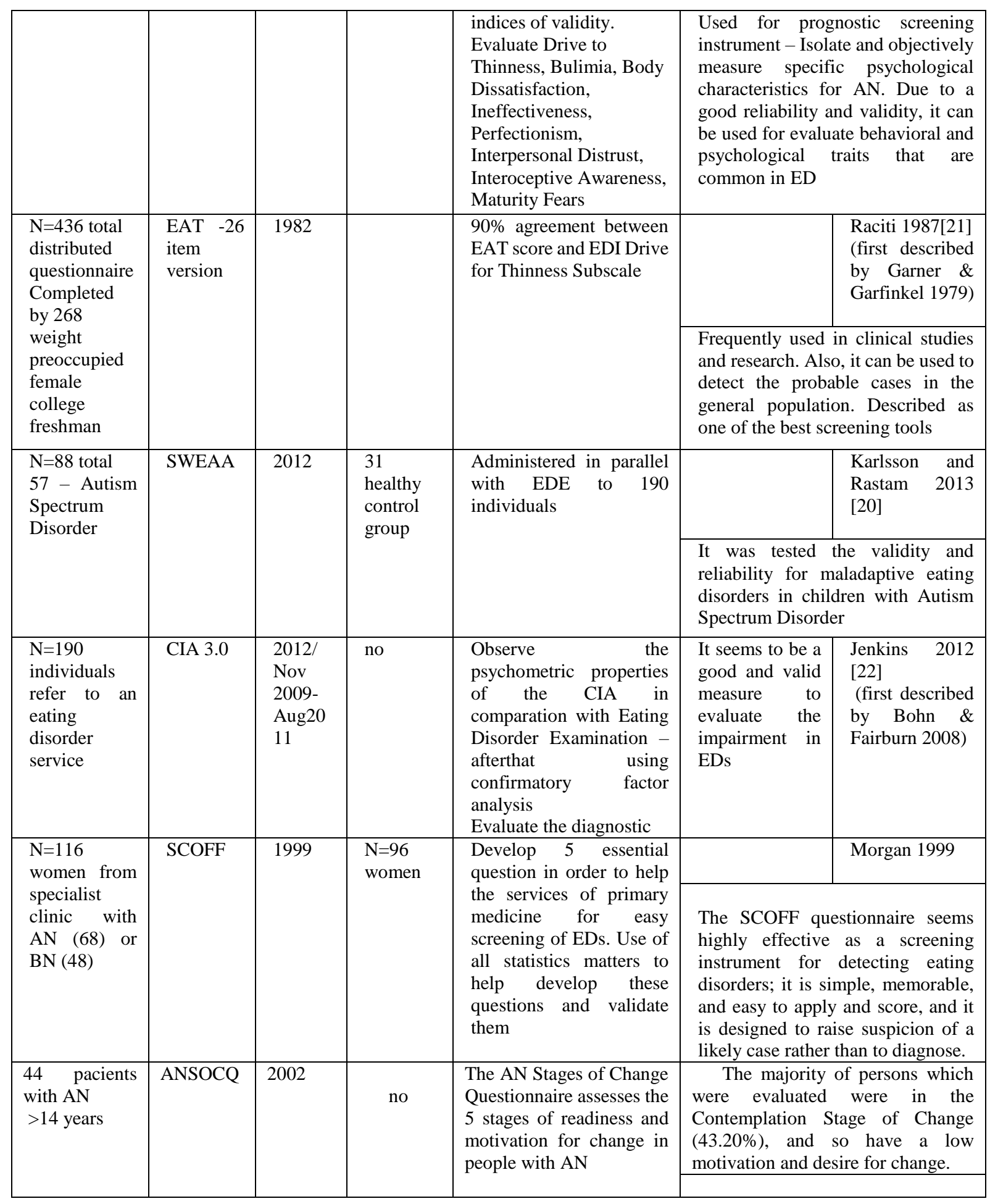

